\section{() OPEN ACCESS}

\title{
Faecal immunochemical test after negative colonoscopy may reduce the risk of incident colorectal cancer in a population-based screening programme
}

\author{
Szu-Min Peng, ${ }^{1}$ Wen-Feng Hsu, ${ }^{2}$ Ying-Wei Wang, ${ }^{3}$ Li-Ju Lin, ${ }^{3}$ Amy Ming-Fang Yen 다, ${ }^{4}$

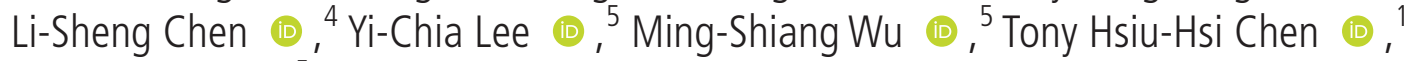

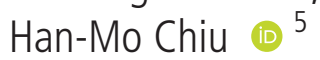

${ }^{1}$ Division of Biostatistics, College of Public Health, National

Taiwan University, Taipei, Taiwan ${ }^{2}$ Department of Internal

Medicine, National Taiwan University Cancer Center, Taipei, Taiwan

${ }^{3}$ Health Promotion

Administration, Ministry of Health and Welfare, Taipei, Taiwan

${ }^{4}$ School of Oral Hygiene, College of Oral Medicine, Taipei Medical University, Taipei, Taiwan ${ }^{5}$ Department of Internal Medicine, National Taiwan University Hospital, Taipei, Taiwan

Correspondence to Dr Han-Mo Chiu, Department of Internal Medicine, National Taiwan University Hospital, Taipei 100225, Taiwan; hanmochiu@ntu.edu.tw

Digestive Disease Week 2019, San Diego, USA. (May 20, 2019; MO 1711)

Received 26 January 2020 Revised 15 August 2020 Accepted 6 September 2020 Published Online First 28 September 2020

Check for updates

(C) Author(s) (or their employer(s)) 2021. Re-use permitted under CC BY-NC. No commercial re-use. See rights and permissions. Published by BMJ.

To cite: Peng S-M, Hsu W-F, Wang Y-W, et al. Gut

2021:70:1318-1324.

\section{ABSTRACT}

Objective Subjects with a positive faecal

immunochemical test (FIT) have a much higher likelihood of advanced neoplasms than the general population. Whether FIT-positive subjects with negative colonoscopy should receive subsequent FIT screening remain unclear.

Design Subjects with a negative colonoscopy after positive FIT in the first screening in the Taiwanese Colorectal Cancer (CRC) Screening Program 2004-2009 were followed until the end of 2014. CRC incidence was compared between those who did and did not receive subsequent FIT screening. Cox regression analysis was conducted, adjusting for major confounders to investigate whether subsequent FIT was associated with lower risk of incident CRC.

Results The study cohort was comprised of 9179 subjects who had negative diagnostic colonoscopy after positive FIT in 2004-2009, of whom 6195 received subsequent FIT during the study period. The CRC incidence (per 1000 person years) was 1.34 in those who received subsequent FIT and 2.69 in those who did not, with corresponding adjusted HR (aHR) of 0.47 (95\% Cl 0.31 to 0.71). Lower adenoma detection rate of diagnostic colonoscopy was associated with higher risk of incident CRC but became non-significant in multivariable analysis after adjustment for subsequent FIT. Higher baseline faecal haemoglobin concentration (FHbC, $\mu \mathrm{g}$ haemoglobin/g faeces) was associated with increased risk of incident CRC (reference: $\mathrm{FHbC}=20-39$; $\mathrm{aHR}=1.93$ (1.04-3.56), 0.95 (0.45-2.00), 2.26 (1.16-4.43) and 2.44 (1.44-4.12) for $\mathrm{FHbC}=40-59$, 60-99, 100-149 and $\geq 150$, respectively).

Conclusion Subsequent FIT should be scheduled after negative colonoscopy to detect missed neoplasms and reduce the risk of incident CRC in a national FIT screening programme.

\section{INTRODUCTION}

Screening has proven effective in reducing mortality from and the incidence of colorectal cancer (CRC), so that population CRC screening programmes have been launched in recent decades in many regions with moderate-to-high CRC incidence. ${ }^{1-6}$ The faecal immunochemical test (FIT) is currently

\section{Significance of this study}

What is already known on this subject?

- Faecal immunochemical test (FIT) positive subjects have higher likelihood of having advanced adenoma or invasive cancer.

- Whether those with negative colonoscopy after FIT screening should receive subsequent FIT screening or go for surveillance colonoscopy 10 years later remain unclear.

What are the new findings?

- Those who received subsequent FIT after negative colonoscopy had significantly lower risk of incident colorectal cancers (CRCs) compared with those who did not.

- Incident CRCs that occurred in those who received subsequent FIT were at a much lower in stage than CRCs diagnosed in those who did not, and baseline faecal haemoglobin concentration was associated with the risk of incident CRC

- Subsequent FIT could offset the risk of incident CRC caused by inadequate colonoscopy quality.

How might it impact on clinical practice in the foreseeable future?

- Risk of incident CRC after negative colonoscopy (colonoscopy interval cancer) can be reduced by subsequent FIT in a FIT screening programme.

- Baseline faecal haemoglobin concentration can help tailor subsequent FIT screening for those with a higher likelihood of developing incident CRC.

one of the most popular tests for population CRC screening, especially in regions where colonoscopy capacity or workforce is constrained. Its effectiveness in reducing CRC mortality or incidence has been demonstrated in several cohort studies from those existent programmes. ${ }^{7-10}$

The currently recommended surveillance interval after negative colonoscopy is 10 years, based mainly on the findings from colonoscopy-based screening studies. Those studies include cohort 
or case-control studies that found that a negative colonoscopy was associated with a substantially reduced risk of developing CRC within 10 years or even longer among low-to-moderate risk individuals. ${ }^{31112}$ Whether subjects with a negative colonoscopy in a FIT-based screening programme can also be advised to go for surveillance colonoscopy at 10 -year intervals, whether the time should be shorter or whether to advise subsequent FIT screening remains controversial. ${ }^{13} 14$ FIT-positive subjects represent a population with a very high-risk profile of CRC; data from the Taiwanese CRC Screening Program revealed that the prevalence of CRC and advanced adenoma in FIT-positive subjects was $5 \%$ and $14 \%$, respectively, equivalent to a 20 -fold to 30 -fold higher risk of CRC and a 4-fold to 5-fold higher risk of advanced adenoma, as compared with the general population. It is therefore reasonable to speculate that any lesion missed by colonoscopy in a FIT-positive subject is more likely to have advanced histology, including invasive cancer. Accordingly, it is questionable whether it is appropriate to deem negative colonoscopy in FIT screening programmes as equivalent to negative findings in the primary screening colonoscopy setting. Providing FIT after negative colonoscopy may be a simple and feasible approach enabling detection of advanced neoplasms, thereby avoiding incident CRC or detecting CRC at an lower stage. The aim of this study was to compare the risk of incident CRC in subsets of populations that did and did not receive subsequent FIT screening after negative colonoscopy in the Taiwanese CRC Screening Program.

\section{MATERIALS AND METHODS}

\section{Taiwanese CRC Screening Program and study population}

The Taiwanese CRC Screening Program was launched in 2004 and biennial FIT was offered to the population aged $50-75$ years (initial upper age limit was 69 years, but this was extended to 75 in 2013). Screening kits were delivered either via regional health bureaus and health centres (outreach screening service) or via clinics or hospitals (inreach screening service). The details of this programme have been described elsewhere. ${ }^{715}$ The relevant data for this nationwide screening programme, including participation in FIT screening, results of FIT and the findings of diagnostic colonoscopy, are all stored in a central screening database at the Health Promotion Administration of the Taiwanese government, which is linked to the Taiwan Cancer Registry, from which the events of incident CRC could be ascertained and verified. The coverage rate of this registry is reported to be $98.6 \%$, with accuracy greater than $99 \% .^{16}$

In our programme, those who have neoplasms detected at colonoscopy are recommended to receive follow-up colonoscopy at different surveillance intervals based on the endoscopic finding, as recommended by major guidelines. ${ }^{13}$ For those with negative colonoscopy, no strict surveillance guidance is provided and people could either choose to receive 10-year colonoscopy surveillance or to continue biennial FIT screening. The current study cohort included subjects who had a positive FIT at their first screening with negative findings at diagnostic colonoscopy, after excluding those with incomplete colonoscopy, during the period of 2004-2009. This study cohort was followed up until the end of 2014 no matter whether the age of the study subjects had already exceeded the upper age limit of our programme. We ascertained the number, diagnosis year and stage of incident CRC via the linkage of the central screening database to the Taiwan Cancer Registry. This study was approved by the Health Promotion Administration of the Ministry of Health and Welfare of the Taiwanese government, and informed consent was waived for the deidentified data.

\section{Faecal immunochemical test}

One of two FIT kits (OC-SENSOR, Eiken Chemical, Tokyo, Japan and HM-JACK, Kyowa Medex, Tokyo, Japan) was provided based on the purchasing policy of the individual municipality or hospital, and a single-spot stool sample was used for testing in this screening programme. A positive test was defined as a result above the defined cut-off of $20 \mu \mathrm{g}$ haemoglobin $(\mathrm{Hb}) / \mathrm{g}$ faeces. Test results of FIT, including the measurements of faecal $\mathrm{Hb}$ concentration (FHbC), were stored in the screening database of the regional and central governments and all participants were notified of the results by mail and telephone. Participants with positive tests were then referred for colonoscopy as a diagnostic examination within 6 months. The cut-off and number of FIT used for first screening, subsequent screenings and after negative colonoscopy were completely the same.

\section{Definitions}

Negative colonoscopy in this study refers to a colonoscopy without the finding of any neoplastic lesion, including invasive cancer, advanced or non-advanced adenoma and traditional or sessile serrated adenoma.

Only invasive cancers were counted as CRC in this study and American Joint Committee on Cancer (AJCC) seventh system was used for staging. As for incident CRC, only those occurred 1.5 years or longer after colonoscopy was counted because sometimes biennial FIT screening might have happened earlier than 2 years, which was dependent on the timing of screening activities that took place in individual municipalities or screening sites.

The adenoma detection rate (ADR) was defined as the number of subjects who had neoplastic findings per 100 colonoscopies performed after a positive FIT. In the current study, we used hospital-level ADR as a measure of adenoma detection, because endoscopist-level ADR could not be ascertained. Colonoscopy was defined as complete if the landmarks of the cecum could be visualised by the colonoscope. In this study, interval cancer refers to colonoscopy interval cancer (IC), as defined by World Endoscopy Organization, which refers to CRC that occurred within 10 years after index-negative colonoscopy, excluding those that were detected by subsequent FIT screening. ${ }^{17}$ All subjects were traced until the end of 2014, even though they have exceeded the age range of our screening programme.

\section{Statistical analysis}

Descriptive data were reported as proportions or means with $\pm \mathrm{SD}$. The incidence of CRC was calculated and reported as the number of events per 1000 person years. Timing of subsequent FIT screening was stratified to five time windows based on the interval between baseline-negative colonoscopy and subsequent FIT: $1.5-3$ years, $3-5$ years and $>5$ years. ADR was categorised as three groups, with hospital-based ADR below first quantile $(<42 \%)$, between first and third quantile (42\%-49\%), and above third quantile (>49\%). Subjects were censored at the end of study period if no incident CRC occurred.

Two Cox proportional HR models were created to estimate $\mathrm{HR}$, adjusting for major confounders to investigate whether subsequent FIT was associated with lower risk of incident CRC and to identify the other risk factors. In the univariate analysis, the risk of incident CRC in relation to age, gender, the interval between negative colonoscopy and subsequent FIT (1.5-3 years, 3-5 years, $>5$ years, no subsequent FIT), hospital-level ADR $(<42 \%, 42 \%-49 \%,>49 \%)$ and FHbC (20-39, 40-59, 60-99, $100-149,>150 \mu \mathrm{g} \mathrm{Hb} / \mathrm{g}$ faeces), family history of CRC in firstdegree relatives, FIT brand was investigated; factors with a $p$ 


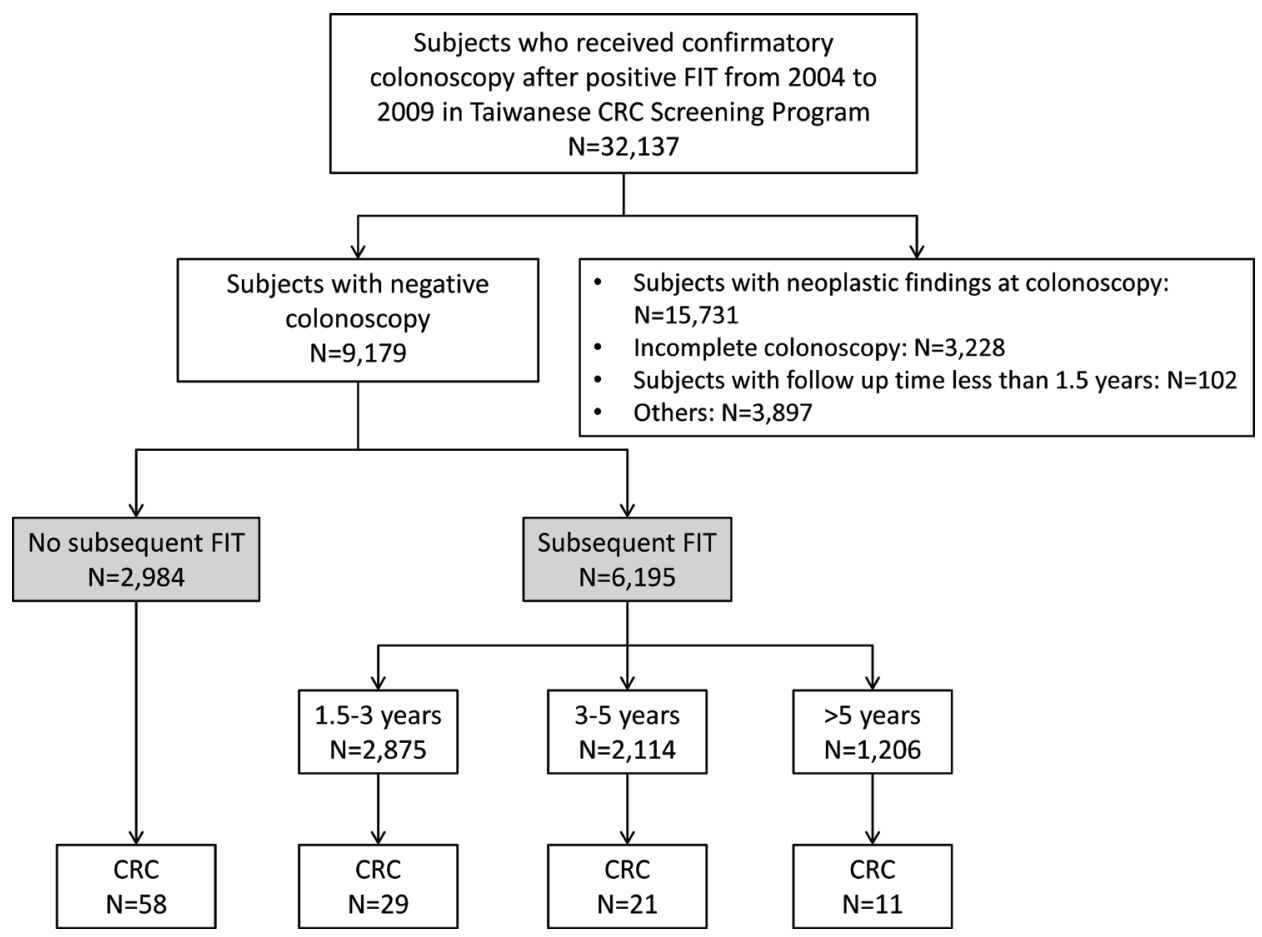

Figure 1 Flow diagram demonstrating the process of identifying study cohort. CRC, colorectal cancer; FIT, faecal immunochemical test.

value $<0.1$ were then included in the multivariable analyses. Model 1, in addition to the presence of subsequent FIT, was adjusted for other confounders such as age at colonoscopy, gender, completeness of colonoscopy, hospital-level ADR and FHbC. In model 2, subsequent FIT was stratified into different time windows and adjusted together with those confounders that were included in model 1. All statistical analyses were performed with SAS V.9.4 (SAS Institute).

\section{RESULTS}

During the period from January 2004 to December 2009, 32 137 subjects received complete colonoscopy after positive FIT at first screening. After excluding those with neoplastic lesions being detected at colonoscopy, incomplete colonoscopy, CRC occurred prior to subsequent FIT round, death from causes other than CRC within 2 years, or missing demographic or FHbC data, a total of 9179 subjects who had no neoplastic finding comprised the study cohort (figure 1). Of them, 6195 subjects received subsequent FIT after colonoscopy during the study period. The demographics, the number of subjects who received subsequent FIT at different time windows, the number of incident CRCs and hospital-level ADR are shown in table 1.

The number of positive FITs, the positivity rate and the number and incidence rate of CRC in those who did and did not receive subsequent FIT are shown in table 2. The incidence of CRC was 1.34 (95\% CI 1.31 to 1.37 ) and 2.69 (95\% CI 2.61 to 2.77 ) per 1000 person years in those who did and did not receive subsequent FIT, respectively. Of those who received subsequent FIT, the incidence was 1.46 (95\% CI 1.40 to 1.53$)$ at $<3$ years, 1.35 (95\% CI 1.30 to 1.40$)$ at $3-5$ years and 1.08 (95\% CI 1.03 to $1.13)$ at $>5$ years. The number of incident CRCs in relation to time and cancer stage is shown in figure 2 and table 3.

The results of univariate and multivariable analyses are given in table 4. In model 1, the adjusted HR (aHR) of incident CRC was $0.47(95 \% \mathrm{CI}=0.31$ to 0.71$)$ in subjects who received subsequent FIT screening compare with those with no subsequent FIT. In model 2, the aHR of incident CRC was 0.53 (95\% CI $=0.32$ to 0.88 ) for those who received a subsequent FIT in $1.5-3$ years, 0.45 (95\% CI 0.26 to 0.79 ) in $3-5$ years and 0.37 (95\% CI 0.18 to 0.77 ) in $>5$ years. Although lower ADR was significantly associated with increased risk of developing

\begin{tabular}{lc}
\hline Table 1 Demographics of the study cohort & \\
\hline Characteristics & \\
\hline Age, mean (SD) & $58.0(5.8)$ \\
\hline Male gender, $\mathrm{n}(\%)$ & $3640(39.7)$ \\
\hline Subjects with negative colonoscopy, $\mathrm{n}$ & 9179 \\
\hline $\begin{array}{l}\text { Time windows that subjects received subsequent FIT after negative } \\
\text { colonoscopy, } \mathrm{n}\end{array}$ & 6195 \\
\hline$<3$ years & 2875 \\
\hline $3-5$ years & 2114 \\
\hline$>5$ years & 1206 \\
\hline Incident CRC after negative colonoscopy, $\mathrm{n}$ & 119 \\
\hline Adenoma detection rate & \\
\hline$<42 \%$ & 2605 \\
\hline 42\%-49\% & 3276 \\
\hline$\geq 50 \%$ & 3298 \\
\hline CRC family history in first-degree relatives & 155 \\
\hline Yes & 9024 \\
\hline No & \\
\hline FIT brands & \\
\hline Initial round & \\
\hline OC-Sensor & 6749 \\
\hline HM-JACK & 2430 \\
\hline Subsequent FIT after colonoscopy & 4118 \\
\hline OC-Sensor & 2036 \\
\hline HM-JACK & 41 \\
\hline Missing brand info & \\
\hline CRC, colorectal cancer; FIT, faecal immunochemical test. \\
\hline
\end{tabular}


Table 2 Incidence of colorectal cancer after negative colonoscopy in relation to the interval between negative colonoscopy and subsequent FIT screening

\begin{tabular}{|c|c|c|c|c|c|c|}
\hline & $\begin{array}{l}\text { Subject } \\
\text { number }\end{array}$ & $\begin{array}{l}\text { Positive test at } \\
\text { subsequent FIT, n }\end{array}$ & $\begin{array}{l}\text { Positivity rate at subsequent } \\
\text { FIT }(\%)\end{array}$ & CRC cases, $\mathrm{n}$ & Person-year & $\begin{array}{l}\text { Incidence per } 1000 \text { person-year } \\
(95 \% \mathrm{Cl})\end{array}$ \\
\hline \multicolumn{7}{|c|}{ Subjects who received subsequent FIT } \\
\hline Overall & 6195 & 703 & 11.3 & 61 & 45580.98 & $1.34(1.31$ to 1.37$)$ \\
\hline $1.5-3$ years & 2875 & 290 & 10.1 & 29 & 19800.10 & 1.46 (1.40 to 1.53$)$ \\
\hline $3-5$ years & 2114 & 240 & 11.4 & 21 & 15575.80 & 1.35 (1.30 to 1.40$)$ \\
\hline$>5$ years & 1206 & 173 & 14.3 & 11 & 10205.08 & 1.08 (1.03 to 1.13$)$ \\
\hline No subsequent FIT & 2984 & - & - & 58 & 21561.52 & 2.69 (2.61 to 2.77$)$ \\
\hline \multicolumn{7}{|l|}{ By FIT brand } \\
\hline OC-Sensor & 4118 & 424 & 10.3 & 43 & 30315.31 & $1.42(1.35$ to 1.49$)$ \\
\hline HM-Jack & 2036 & 275 & 13.5 & 18 & 14865.74 & $1.21(1.15$ to 1.27$)$ \\
\hline Missing brand info & 41 & 4 & 9.8 & 0 & 399.93 & 0 \\
\hline
\end{tabular}

CRC, colorectal cancer; FIT, faecal immunochemical test.

incident CRC in univariate analysis, with an HR of $1.66(95 \%$ CI 1.01 to 2.72 ) for ADR of $42 \%-49 \%$ and 1.96 (95\% CI 1.19 to 3.23 ) for $\mathrm{ADR}$ of $<42 \%$, it became non-significant or less significant in multivariable analysis. Higher FHbC was also associated with increased risk of incident CRC, with an aHR of 1.93 (95\% CI 1.04 to 3.56) for FHbC of 40-59, 0.95 (95\% CI 0.45 to 2.00 ) for $60-99,2.26$ (95\% CI 1.16 to 4.43 ) for 100-140 and 2.44 (95\% CI 1.44 to 4.12 ) for FHbC of $\geq 150 \mu \mathrm{g} \mathrm{Hb} / \mathrm{g}$ faeces, compared with those having an FHbC of 20-39 $\mu \mathrm{g} \mathrm{Hb} / \mathrm{g}$ faeces.

\section{DISCUSSION}

Incident CRCs occurring after negative colonoscopy may affect the effectiveness of a screening programme. In the current study, we demonstrated that subsequent FIT after negative colonoscopy remarkably reduced the risk of incident CRC with a HR of 0.47 in a population receiving FIT-based screening. The stage of incident CRC was much lower in those who received subsequent FIT screening (CRC lower than stage 2: $52.7 \%$ vs $23.7 \%$ ) than in those who did not, implying that offering FIT after negative colonoscopy may enhance early detection, thereby improving the effectiveness of the entire screening programme. The data demonstrated herein provide new insight into optimising a FIT screening programme.

Previous studies have demonstrated that missed neoplasms, especially missed cancers or advanced adenoma, were responsible for the majority of colonoscopy interval cancers or
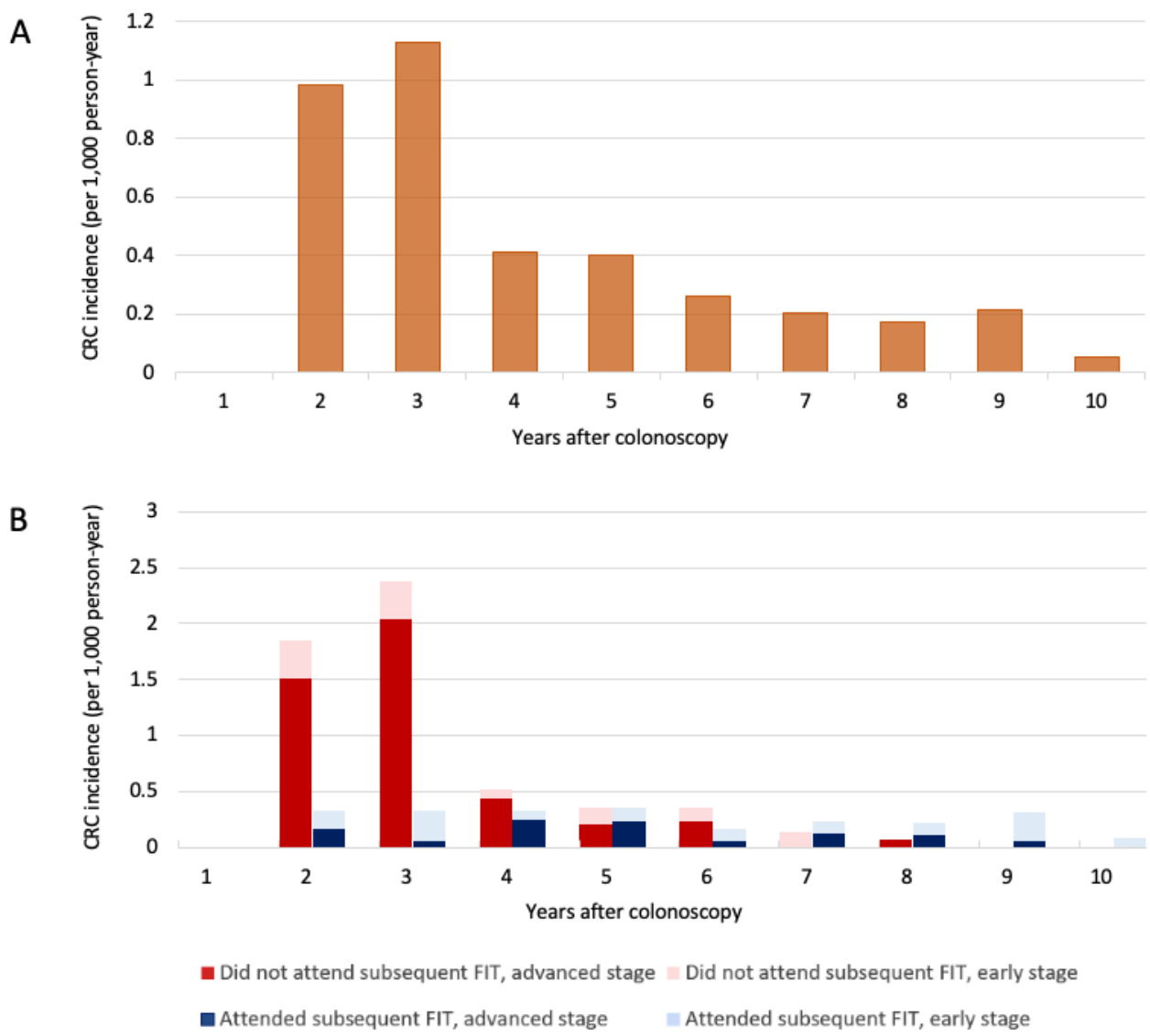

Figure 2 Incidence of CRC in relation to time after negative colonoscopy. (A) Whole cohort. (B) Stratified with subsequent FIT screening and CRC stage. CRC, colorectal cancer; FIT, faecal immunochemical test. 
Table 3 Number of CRC in relation with stage and detection mode in those who did and did not receive subsequent FIT

\begin{tabular}{|c|c|c|c|c|c|c|}
\hline \multirow[b]{3}{*}{ CRC stage } & \multicolumn{6}{|c|}{ Subsequent FIT } \\
\hline & \multicolumn{3}{|l|}{ No } & \multicolumn{3}{|l|}{ Yes } \\
\hline & Stage 1 & Stage 2-4 & NA & Stage 1 & Stage $2-4$ & NA \\
\hline Overall, $n$ & $12(23.1 \%)$ & $40(76.9 \%)$ & 6 & $29(52.7 \%)$ & $26(47.3 \%)$ & 6 \\
\hline Screen detected, $\mathrm{n}$ & - & - & - & $22(57.9 \%)$ & $16(42.1 \%)$ & 5 \\
\hline Interval cancer, n & $12(23.1 \%)$ & 40 (76.9\%) & 6 & $7(41.2 \%)$ & $10(58.8 \%)$ & 1 \\
\hline
\end{tabular}

CRC, colorectal cancer; FIT, faecal immunochemical test; NA, non applicable.

postcolonoscopy CRCs. ${ }^{15} 1819$ In this context, the main purpose of subsequent FIT is to reveal overlooked significant neoplasms, and partially to detect newly developed ones. In the current study, the risk of incident CRC was lower in the group that received FIT during 3-5 years after a negative colonoscopy, as compared with those who received FIT at 1.5-3 years, and the risk was lowest in those who received subsequent FIT at 5 years or later. Such findings are not difficult to explain if the natural course of colorectal neoplasms is taken into consideration. For example, if an advanced adenoma was previously missed by colonoscopy, then offering FIT within 3 years after colonoscopy might have helped to prevent the occurrence of CRC, but when the duration is longer than 3 years, then a higher proportion of advanced adenomas may transform into invasive cancers, leading to a higher incidence of CRC. Such a finding is consistent with previous studies estimating the sojourn time of 3 years for an advanced adenoma to become an invasive cancer. ${ }^{2021} \mathrm{We}$ also found that the risk of incident CRC was lowest in those who received subsequent FIT at the fifth year or later. Such a finding should not be misinterpreted as meaning that later timing of subsequent FIT is more effective in reducing incident CRC. Rather, it should indicate that those whose asymptomatic invasive cancers were missed at baseline colonoscopy might have already progressed into an advanced stage and be diagnosed as having symptomatic CRC (colonoscopy interval cancers) at that timing and were categorised as CRC occurring in the 'no subsequent FIT screening' group. Such speculation is supported by previous studies showing that about one-fifth of early stage CRCs will progress into advanced stage CRCs annually; therefore, they are more likely to become symptomatic and diagnosed clinically rather than being detected by the screening programme within such a timeframe. ${ }^{22}$ We therefore propose that 2 years after colonoscopy would be the optimal time to offer a subsequent FIT, if the main purpose is to detect both missed cancers and advanced adenomas.

Another important finding of this study is that subsequent FIT was able to ameliorate the effect of inadequate colonoscopy quality. Several studies have demonstrated that ADR is one of the most important quality measurements for colonoscopy, and some have shown its strong association with incident CRC, advanced stage CRC or even CRC death. ${ }^{152324}$ In this study, the overall ADR during the study period was $45.5 \%$, which was above the benchmark threshold for FIT-positive subjects. ${ }^{25}$ Nevertheless it was evident that a lower hospital-level ADR was associated with the risk of developing incident CRC as demonstrated by the univariate analysis (table 4). The effect of hospital-level ADR was offset by subsequent FIT screening, a result supported by the finding of non-significant or less significant effect of low $\mathrm{ADR}$ on incident CRC risk in the fully adjusted multivariable

Table 4 Multivariable analyses on the risk of incident CRC in relation to subsequent FIT with different time windows and other factors

\begin{tabular}{|c|c|c|c|}
\hline & \multirow[b]{2}{*}{ Crude HR $(95 \% \mathrm{Cl})$} & \multicolumn{2}{|c|}{ Adjusted HR $(95 \% \mathrm{Cl})$} \\
\hline & & Model 1 & Model 2 \\
\hline Age & 1.02 (0.99 to 1.06$)$ & 1.00 (0.96 to 1.03$)$ & $1.00(0.96$ to 1.03$)$ \\
\hline \multicolumn{4}{|l|}{ Gender } \\
\hline Male vs female & 1.37 (0.93 to 2.01$)$ & $1.23(0.83$ to 1.81$)$ & $1.23(0.84$ to 1.81$)$ \\
\hline \multicolumn{4}{|l|}{ Subsequent FIT } \\
\hline No & 1 & Ref & 1 \\
\hline Yes & 0.44 (0.30 to 0.64$)$ & $0.47(0.31$ to 0.71$)$ & - \\
\hline $1.5-3$ years & 0.48 (0.29 to 0.77$)$ & - & 0.53 (0.32 to 0.88$)$ \\
\hline $3-5$ years & 0.43 (0.25 to 0.74$)$ & - & $0.45(0.26$ to 0.79$)$ \\
\hline$>5$ years & 0.36 (0.18 to 0.74$)$ & - & $0.37(0.18$ to 0.77$)$ \\
\hline \multicolumn{4}{|c|}{ Adenoma detection rate } \\
\hline$>49 \%$ & Ref & ref & ref \\
\hline $42 \%-49 \%$ & 1.66 (1.01 to 2.72$)$ & 1.42 (0.86 to 2.34 ) & 1.47 (0.89 to 2.43$)$ \\
\hline$<42 \%$ & 1.96 (1.19 to 3.23$)$ & 1.61 (0.97 to 2.67 ) & $1.66(1.00$ to 2.77$)$ \\
\hline \multicolumn{4}{|c|}{$\mathrm{FHbC}$ of baseline FIT ( $\mu \mathrm{g}$ hemoglobin/g faeces) } \\
\hline 20-39 & Ref & Ref & Ref \\
\hline $40-59$ & 1.98 (1.07 to 3.66$)$ & 1.94 (1.05 to 3.58$)$ & 1.93 (1.04 to 3.56$)$ \\
\hline $60-99$ & 1.00 (0.47 to 2.11$)$ & 0.95 (0.45 to 2.01$)$ & 0.95 (0.45 to 2.00$)$ \\
\hline $100-149$ & 2.40 (1.23 to 4.70$)$ & 2.28 (1.17 to 4.46$)$ & 2.26 (1.16 to 4.43$)$ \\
\hline$\geq 150$ & 2.59 (1.54 to 4.37$)$ & 2.46 (1.45 to 4.15$)$ & 2.44 (1.44 to 4.12$)$ \\
\hline \multicolumn{4}{|c|}{ CRC family history in first-degree relatives } \\
\hline No & Ref & - & - \\
\hline Yes & $1.11(0.27$ to 4.50$)$ & - & - \\
\hline \multicolumn{4}{|l|}{ FIT kit } \\
\hline HM-JACK & Ref & - & - \\
\hline OC-Sensor & $1.15(0.63$ to 2.10$)$ & - & - \\
\hline
\end{tabular}

CRC, colorectal cancer; FHbC, faecal haemoglobin concentration; ; FIT, faecal immunochemical test. 
models. This result implies that subsequent FIT may be used to compensate for the compromised screening effectiveness caused by inadequate colonoscopy quality. The positivity rate of $11.3 \%$ of subsequent FIT was rather high, but the positive predictive value of $8.68 \%$, translated to a 'number needed to FIT' of 102 and an affordable 'number needed to scope' of 12 to detect one CRC, justifies such an approach. In this study, we also observed an association of higher $\mathrm{FHbC}$ with an increased risk of incident CRC. Such a finding also gives new insight into the future development of a tailored or risk-based surveillance strategy in a negative colonoscopy population based on their baseline $\mathrm{FHbC}$, and therefore enables us to further target the population who would be most likely benefit from the subsequent FIT. To which extent that such a subsequent FIT screening approach can contribute to the effectiveness of screening (episode or programme sensitivity) is another intriguing issue. ${ }^{26} \mathrm{~A}$ rough estimate from the magnitude of reducing incident CRC in this study, the proportion that colonoscopy IC account for non-screening detected CRC (including FIT IC, colonoscopy IC, CRC in non-complier to colonoscopy) in our programme and the proportion of colonoscopy IC that occurred in subjects with negative colonoscopy, $1 \%-2 \%$ improvement of episode sensitivity could be expected, but its magnitude is also dependent on the compliance to colonoscopy and its quality.

This study has several strengths. First, the large population size of this screening programme allowed for more comprehensive analyses by adjusting for major factors that might have affected the risk of incident CRC and allowed us to make more precise estimations of risk. Second, we linked our screening database to the National Cancer Registry, which has a very high coverage rate and accuracy and increased the validity of our study. ${ }^{16}$ Third, enrolling subjects who received screening during 20042009 and tracking them until 2014 enabled us to follow-up this cohort for a sufficiently long period, which is necessary for outcome events (incident CRC) to occur if the progression rate or sojourn time of colorectal neoplasms is taken into consideration. ${ }^{21}{ }^{27}$ Nevertheless, this study is not without limitations. First, this is not a randomised trial; thus, some confounders and self-selection might exist. In other words, those who presented at a subsequent FIT screening might have a healthier lifestyle, a better diet or greater awareness of CRC screening, any of which might have affected those results, leading to the lower risk for incident CRC and overestimation of the effect of subsequent FIT screening. Second, although our results showed that offering a FIT during the surveillance interval may help in detecting significant neoplasms that were missed by a previous colonoscopy, our results may not be completely applicable to the colonoscopy-based screening setting, because FIT positivity actually represents a very high-risk population at much higher risk of advanced adenoma and CRC than the general population. ${ }^{15}$ Lane et al reported on subjects who had a family history of CRC or past neoplasms. Those who had repeated FIT had an almost twofold decrease in their risk for cancer and advanced adenoma compared with patients who were not tested. The researchers concluded that interval FIT can be used to detect missed or rapidly developing lesions in surveillance programmes sooner than surveillance colonoscopy can. ${ }^{28}$ Further study in the primary colonoscopy screening setting is warranted. Third, we used hospital-level rather than endoscopist-level ADR in this study, which may have underestimated the effect of low ADR. Fourth, we did not explore whether more than one subsequent FITs would provide even better protection against incident CRC. Owing to the limited number of incident CRC cases, further stratification is not feasible and may increase the uncertainty of risk estimations. Fourth, whether subsequent FIT is really able to reduce CRC mortality could not be elucidated by the findings of the current study because of the paucity of incident CRC cases, the low fatality rate of CRC and the short period of the study. Further study is necessary.

In conclusion, we demonstrated that subsequent FIT could effectively reduce the risk of incident CRC after negative colonoscopy in an FIT screening programme, mainly by detection of missed significant neoplasms. Further exploration is mandatory to further elucidate the appropriate timing and frequency of subsequent FIT and to identify the population such an approach may benefit, based on the level of FHbC.

Twitter Wen-Feng Hsu @Wen-Feng

Acknowledgements We would like to express our most sincere gratitude and appreciation to professor Dennis Ahnen of University of Colorado for his constructive and insightful suggestion during the presentation of this study in the Digestive Disease Week 2019 in San Diego, USA.

Contributors Conception and design of the study: H-MC, M-SW, TH-HC. Generation, collection, assembly, analysis and/or interpretation of data: S-MP, H-MC, W-FH, AM-FY, SL-SC, Y-CL, Y-WW, L-JL. Drafting and revision of the manuscript: S-MP, H-MC, TH-HC. Approval of the final version of the manuscript: all authors.

Funding This study was supported by the Health Promotion Administration, Ministry of Health and Welfare (A1011119, A1021227, A1031135, A1041122, A1051013, and A1061224) of Taiwanese government. The funding source had no role in study design, data collection, analysis, or interpretation, report writing, or the decision to submit this paper for publication.

Competing interests None declared.

Patient and public involvement Patients and/or the public were not involved in the design, or conduct, or reporting, or dissemination plans of this research.

Patient consent for publication Not required.

Provenance and peer review Not commissioned; externally peer reviewed.

Data availability statement Data may be obtained from a third party and are not publicly available. Taiwan Colorectal Cancer Screening Program database in Health Promotion Administration of Taiwanese government. Information on colorectal cancers from Taiwan Cancer Registry database (http://tcr.cph.ntu.edu.tw/main.php? Page $=\mathrm{N} 1$ )

Open access This is an open access article distributed in accordance with the Creative Commons Attribution Non Commercial (CC BY-NC 4.0) license, which permits others to distribute, remix, adapt, build upon this work non-commercially, and license their derivative works on different terms, provided the original work is properly cited, appropriate credit is given, any changes made indicated, and the use is non-commercial. See: http://creativecommons.org/licenses/by-nc/4.0/.

\section{ORCID iDs}

Amy Ming-Fang Yen http://orcid.org/0000-0002-0628-8768

Li-Sheng Chen http://orcid.org/0000-0002-5799-6705

Yi-Chia Lee http://orcid.org/0000-0002-8160-1216

Ming-Shiang Wu http://orcid.org/0000-0001-5325-3974

Tony Hsiu-Hsi Chen http://orcid.org/0000-0002-5799-6705

Han-Mo Chiu http://orcid.org/0000-0003-2786-8056

\section{REFERENCES}

1 Hewitson P, Glasziou P, Watson E, et al. Cochrane systematic review of colorectal cancer screening using the fecal occult blood test (Hemoccult): an update. Am J Gastroenterol 2008;103:1541-9

2 Zauber AG, Winawer SJ, O'Brien MJ, et al. Colonoscopic polypectomy and long-term prevention of colorectal-cancer deaths. N Engl J Med 2012;366:687-96.

3 Nishihara R, Wu K, Lochhead P, et al. Long-Term colorectal-cancer incidence and mortality after lower endoscopy. N Engl J Med 2013;369:1095-105.

4 Benson VS, Atkin WS, Green J, et al. Toward standardizing and reporting colorectal cancer screening indicators on an international level: the International colorectal cancer screening network. Int J Cancer 2012;130:2961-73.

5 Schreuders EH, Ruco A, Rabeneck L, et al. Colorectal cancer screening: a global overview of existing programmes. Gut 2015;64:1637-49.

6 Young GP, Rabeneck L, Winawer SJ. The global paradigm shift in screening for colorectal cancer. Gastroenterology 2019;156:843-51.

7 Chiu H-M, Chen SL-S, Yen AM-F, et al. Effectiveness of fecal immunochemical testing in reducing colorectal cancer mortality from the one million Taiwanese screening program. Cancer 2015;121:3221-9. 
8 Zorzi M, Hassan C, Capodaglio G, et al. Long-Term performance of colorectal cancerscreening programmes based on the faecal immunochemical test. Gut 2018;67:2124-2130

9 Levin TR, Corley DA, Jensen CD, et al. Effects of organized colorectal cancer screening on cancer incidence and mortality in a large community-based population. Gastroenterology 2018;155:1383-91.

10 Giorgi Rossi P, Vicentini M, Sacchettini C, et al. Impact of screening program on incidence of colorectal cancer: a cohort study in Italy. Am J Gastroenterol 2015;110:1359-66.

11 Brenner H, Chang-Claude J, Seiler CM, et al. Long-Term risk of colorectal cancer after negative colonoscopy. J Clin Oncol 2011;29:3761-7.

12 Singh $H$, Turner $D$, Xue L, et al. Risk of developing colorectal cancer following a negative colonoscopy examination: evidence for a 10-year interval between colonoscopies. JAMA 2006;295:2366-73.

13 Lieberman DA, Rex DK, Winawer SJ, et al. Guidelines for colonoscopy surveillance after screening and polypectomy: a consensus update by the US Multi-Society Task force on colorectal cancer. Gastroenterology 2012;143:844-57.

14 Hassan C, Quintero E, Dumonceau J-M, et al. Post-polypectomy colonoscopy surveillance: European Society of gastrointestinal endoscopy (ESGE) guideline. Endoscopy 2013;45:842-64.

15 Chiu SY-H, Chuang S-L, Chen SL-S, et al. Faecal haemoglobin concentration influences risk prediction of interval cancers resulting from inadequate colonoscopy quality: analysis of the Taiwanese nationwide colorectal cancer screening program. Gut 2017;66:293-300

16 Chiang C-J, You S-L, Chen C-J, et al. Quality assessment and improvement of nationwide cancer registration system in Taiwan: a review. Jpn J Clin Oncol 2015;45:291-6.

17 Sanduleanu S, le Clercq CMC, Dekker E, et al. Definition and taxonomy of interval colorectal cancers: a proposal for standardising nomenclature. Gut 2015;64:1257-67.
18 le Clercq CMC, Bouwens MWE, Rondagh EJA, et al. Postcolonoscopy colorectal cancers are preventable: a population-based study. Gut 2014;63:957-63.

19 Robertson DJ, Lieberman DA, Winawer SJ, et al. Colorectal cancers soon after colonoscopy: a pooled multicohort analysis. Gut 2014;63:949-56.

20 Brenner $\mathrm{H}$, Altenhofen L, Katalinic A, et al. Sojourn time of preclinical colorectal cancer by sex and age: estimates from the German national screening colonoscopy database. Am J Epidemio/ 2011;174:1140-6.

21 Prevost TC, Launoy G, Duffy SW, et al. Estimating sensitivity and sojourn time in screening for colorectal cancer: a comparison of statistical approaches. Am J Epidemiol 1998;148:609-19.

22 Brenner $\mathrm{H}$, Altenhofen L, Stock C, et al. Prevention, early detection, and overdiagnosis of colorectal cancer within 10 years of screening colonoscopy in Germany. Clin Gastroenterol Hepatol 2015;13:717-23.

23 Kaminski MF, Regula J, Kraszewska E, et al. Quality indicators for colonoscopy and the risk of interval cancer. N Engl J Med 2010;362:1795-803.

24 Corley DA, Jensen CD, Marks AR, et al. Adenoma detection rate and risk of colorectal cancer and death. N Engl J Med 2014;370:1298-306.

25 Robertson DJ, Lee JK, Boland CR, et al. Recommendations on fecal immunochemical testing to screen for colorectal neoplasia: a consensus statement by the US Multi-Society Task force on colorectal cancer. Gastroenterology 2017;152:1217-37.

26 Hakama M, Auvinen A, Day NE, et al. Sensitivity in cancer screening. J Med Screen 2007;14:174-7.

27 Brenner H, Hoffmeister M, Stegmaier C, et al. Risk of progression of advanced adenomas to colorectal cancer by age and sex: estimates based on 840,149 screening colonoscopies. Gut 2007;56:1585-9.

28 Lane JM, Chow E, Young GP, et al. Interval fecal immunochemical testing in a colonoscopic surveillance program speeds detection of colorectal neoplasia. Gastroenterology 2010;139:1918-26. 